\title{
A Study on the Value of Minimalism in Yoshio Taniguchi's Museum
}

\author{
Sooknyung $\mathrm{Ha}^{1}$ \\ ${ }^{1}$ Professor, Spacial Design Major, Sangmyung University, Republic of Korea, snha3430@smu.ac.kr
}

\begin{abstract}
Recently, design work to empty a space has been arousing the interest of many people through the mass media. The phrase 'to empty a space' is synonymous with the meaning of 'to empty', or 'something not there', 'to remove', 'to be tidy'. In the artistic sense,'minimal' implies the meanings of 'excluding decorations','refined images', and 'simple lines or planes'. The beginning of the 20th century tended to be led by the Modern Movement, and by the end of the 60s, many other styles of architecture based on the Ideology of Modernism were formed. As part of the modernism, a new art trend called 'Minimalism' emerged, and it was derived not only into indoor spaces, but also into various fields such as music, culture, movies, fashion, architecture, furniture, and design. Most of all In 1997, the project that drew the greatest attention from the world's architectural world was the architectural design competition of The Museum of Modern Art in New York, the center of modern architecture and contemporary art. It was a difficult task that attracted the attention of the world, as the extension would be built right next to such a famous building, resulting in comparison and evaluation. The final winner was this unexpected figure, Yoshio Taniguchi of Japan. Therefore, in this study the characteristics of minimalism in space are analyzed in connection with the elements that make up the space centered on the museum designed by Yoshio Taniguchi. The analysis items are divided into the elements applied to the design, the connection of the space, and the characteristics of materials, based on which this study attempts to analyze the value of the space. As the method of this study, minimalism was examined through review of literature and previous studies, and characteristics were analyzed through each case on how to express natural elements and plan in connection with certain spatial elements for minimalist design against four art museums designed by Yoshio Taniguchi between 1991 and 2004 through personal visits and excerpts from web searches and literature. As a result of analyzing his work, the characteristics of minimalism of Yoshio Taniguchi are a simple box-shaped structure, implement artificial and natural lightings and the spirit of emptiness. In the early 1990s, Taniguchi pursued a style of creating spaces with elaborate horizontal and vertical divisions, and Inokuma Museum became a decisive moment in completing such a style. Yoshio Taniguchi's works went beyond the refined and minimalist style of European designers and had a subtle oriental lyricism there. While the conflicting concepts of bigness and rusticity flew through neat straight lines and curves, they had a deep meaning. After all, the morphological motif of his minimalism architecture can be found in modernist thoughts of the West, but the philosophical motif and its development can be found in the view of nature of the East.
\end{abstract}

Keywords: Yoshio Taniguchi, Minimalism, Museum, Architectire

\section{Introduction}

In general terms, minimalilsm is based on a process of reduction of architectire down to its essential concepts of spaces, light and form, rather than on mechanisms of subtraction, negation, or absence of

Received: February 20, 2021; 1st Review Result: April 05, 2021; 2nd Review Result: May 24, 2021 Accepted: June 30, 2021 
ornament, or on a eulogy of puritanism. Recently, design work to empty a space has been arousing the interest of many people through the mass media. In the artistic sense,'minimal' implies the meanings of 'excluding decorations','refined images', and 'simple lines or planes'[1].

The beginning of the 20th century tended to be led by the Modern Movement, and by the end of the $60 \mathrm{~s}$, many other styles of architecture based on the Ideology of Modernism were formed. As part of the modernism, a new art trend called 'Minimalism' emerged, and it was derived not only into indoor spaces, but also into various fields such as music, culture, movies, fashion, architecture, furniture, and design. In 1997, the project that drew the greatest attention from the world's architectural world was the architectural design competition of The Museum of Modern Art in New York, the center of modern architecture and contemporary art. This art gallery site is New York's premier hub where bustling 5th and 6th Avenues and 53rd Streets meet. Moreover, the building that stands there is the architecture designed by Edward Durell Stone, an American architect, and has been imprinted in people's minds as a symbol of New York art for decades since 1939. It was a difficult task that attracted the attention of the world, as the extension would be built right next to such a famous building, resulting in comparison and evaluation. Naturally, There was widespread speculation about the winner[2].

Contrary to expectations, Rem Koolhaas was not on the finalist list, instead other contemporary star architects Herzog \& de Meuron Architekten of Switzerland and Bernard Tschumi of France were named. Another candidate was Yoshio Taniguchi of Japan, who, compared to others with the splendor of fame, was a successful architect only in his own country. Taniguchi was a very unfamiliar man with a strange name in Europe and the United States but he was soon declared as the winner. When the result was announced, the media from not only the United States, but also from around the world made a special article that the unknown master of Japan appeared. MoMA selected nine art museums among Yoshio Taniguchi's works to display as the first exhibition to commemorate the reopening in 2004 after all work was completed. Appreciating architecture like a work of art, visitors in the US and Europe, who were well versed in design, then learned why this Japanese architect, who is not well known in the Western world, was chosen by MoMA. His works went beyond the refined and minimalist style of European designers and had a subtle oriental lyricism there. While the conflicting concepts of bigness and rusticity flew through neat straight lines and curves, they had a deep meaning.

As described above, after Yoshio Taniguchi was selected to design the Museum of Modern Art (MOMA), the extensibility of space for minimalist design began to appear. However, based on the previous studies, most of them were on the expressive characteristics of minimalist design for commercial and residential spaces, or on the conceptual considerations of oriental philosophy and ecological minimalist design. Since the Industrial Revolution in the 18th century, humans have been using nature recklessly under the pretext of rapid growth. As a result, material abundance was obtained, but a disconnection between humans and nature was caused. Accordingly, humans need to adapt to nature as it showed ecological crisis of limitation by considering nature as a material means. In view of the results, this study tries to find the meaning of it in relation to the work of Yoshio Taniguchi, who introduced the minimalist museum architecture for the unity of architecture and nature, which deals with the interconnection between human society and nature from an aesthetic point of view in modern society.

\section{Yoshio Taniguchi's Architectural Philosophy and Life}

Yoshio Taniguchi tried to collaborate with artists from various fields in art museum architecture. In collaboration with Isamu Noguchi (lighting designer), a Japanese sculptor, famous for his works expressing his emotions for a space, he completed the courtyard of the Ken Domon Museum of photography in Yamagata Prefecture in 1989, and has also tried collaborating with landscape architect Peter Walker (designer of a memorial installation project for the victims of World Trade Center site in New York). Through this, he realized that architecture should not be done like maverick, but that it 
should be coordinated by integrating the opinions of experts in various fields. This recognition has shone in his many art museum architectures.

Yoshio Taniguchi's art museums, which are harmonized with works, taking into account the movements and emotions of visitors rather than parading architectures themselves, entail comfortable emotions and understanding with concise and neat design. He is an architect who considers how to show the works in the building better than how to show his architecture to museum visitors.

Yoshio Taniguchi had a close relationship with architecture in his background. His father, Yoshiro Taniguchi, was a giant in Japanese architecture. However, Yoshio Taniguchi graduated from the Department of Mechanical Engineering, Keio University, choosing engineering over architecture. However, as he could not shake off the architectural interest that was transmitted through blood, eventually, he changed his course and went to the United States in 1964, where he graduated from the Department of Architecture, Graduate School of Design, and Harvard University. Later, he learned work from the master of modern architecture, Walter Gropius, and then returned to Japan and worked for the studio of Japanese architectural master Kenzo Tange for eight years.

At the time, Yoshio Taniguchi learned the practice of architecture and the Japanese sensitivity of his mentor Kenzo Tange. While mentor Kenzo Tange overwhelmed the 70s with exposed concrete buildings, a modern interpretation of Japanese wooden structures, Taniguchi, who studied in the United States, pursued an architecture with modernity and universality with a more open attitude. He majored in mechanical engineering and was awakened of the precise mechanical details, not just pursuing sophistication, but developing architecture to a level different from existing ideas by working openly with artists from other fields.

\subsection{Scope and Method}

This study is aimed to examine the trend of the times based on previous studies and literature through concepts and theoretical considerations on minimalist trends, and the spatial values of Yoshio Taniguchi. The scope covers the selection and analysis of cases of Yoshio Taniguchi's museum space from the 1900s to the MOMA in 2004, when the minimalist trends, viewing nature, humans, and space as a single entity, was strongly expressed.

\section{Case analysis of Yoshio Taniguchi's Museum}

\subsection{The Museum of Modern Art}

Since its establishment in 1939, MoMA has continuously attempted to create spaces for collections, education, and relaxation. American architect Philip Johnson designed the Abby Aldrich Rockefeller Sculpture Garden and East Wing in 1964, and Cesar Pelli extended the exhibition space in 1984. This partial extension project was enough work for architects to covet. Since then, the largest extension project in MoMA's history was implemented in 1997, and MoMA's importance as a client seems to have been a concern that the value of MoMA, which has a history and philosophy of nearly 80 years, would be damaged if an architect overly focused on maintaining his own style[3]. In MoMA's extension design, Taniguchi conceived that a white box space, called a white cube, is a neutral space that have had the same way as the development of contemporary art. By creating the most minimal space, he attempted to build an art museum where the work is the main character, not the space anywhere in the museum[4].

This is one of the very important construction strategies from the perspective of the client MoMA with a huge collection of Picasso, Jackson Pollock, Liechtenstein. in its long history, but not a newly built art museum. MoMA's architectural curator Terence Reilly, who participated in the judging in person, also confessed in an interview that he was surprised that he was attracted to the unexpected 
architect who had not even built a building outside Japan (maybe a good reason for disqualification) instead of the brilliant works of famous architects.
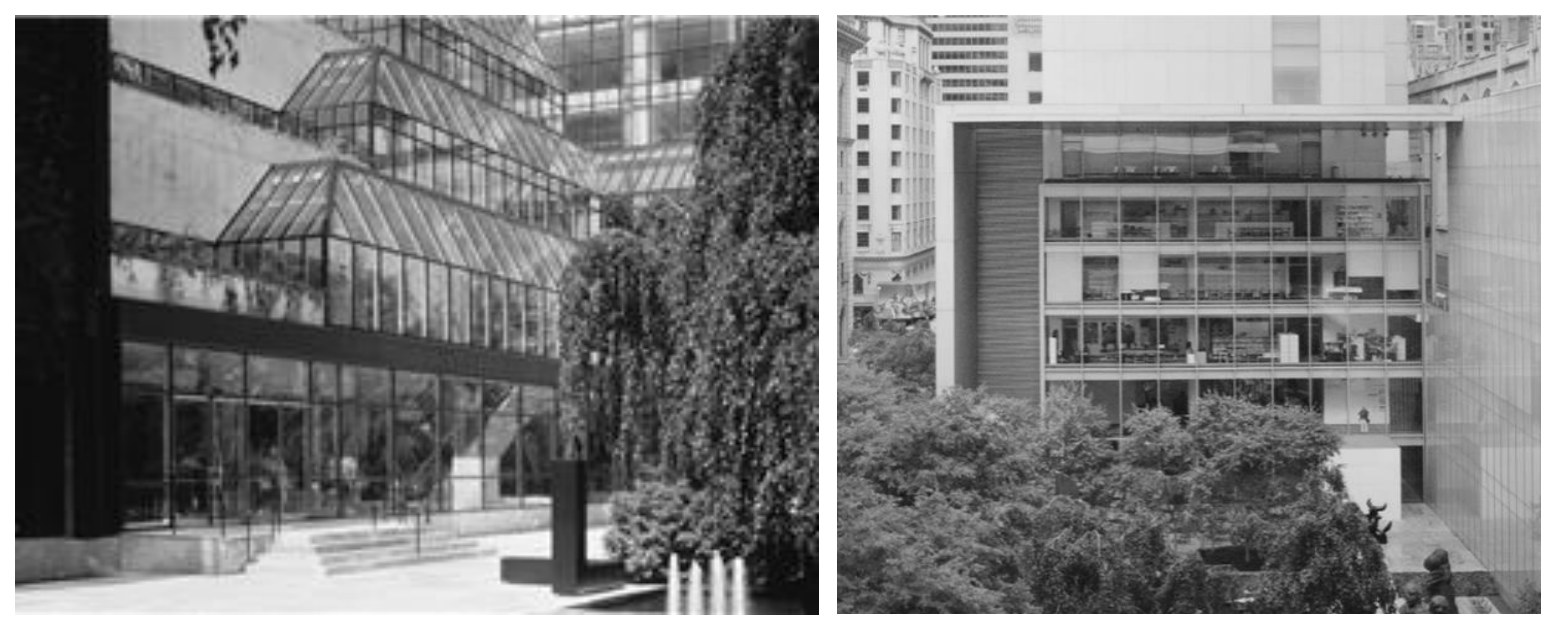

[Fig. 1] MoMA, 1984, West Wing Expension by Cesar Pell(Top) \& MoMA, 2004(Bottom)[5]

In the end, MoMA judges showed their wisdom in choosing an architect who understood their thoughts rather than clinging to the brand value. The interview on the first day of the opening, saying "In my view, it is just incomplete with many loopholes. However, I am comforting myself at the fact that without art, museum architecture should look unfinished, and if it looks finished, it's a very bad museum.", symbolically shows Yoshio Taniguchi's architectural philosophy for "a good art museum."

MoMA's "minimalistic" characteristics can be found in the exterior of the architecture that finally appeared in 2004, but they begun with MoMA's philosophy of conciseness and refinement which were shown before to the completion of the architecture of the century. For the architectural project of the century, European architects took pride in competition, but MoMA's choice was Japanese architect Yoshio Taniguchi, who was almost unknown. Architects of the century came up with a plan to add a variety of designs and techniques to the museum, a symbol of New York and the mecca of world contemporary art, but Taniguchi proposed a thorough emptiness[6].
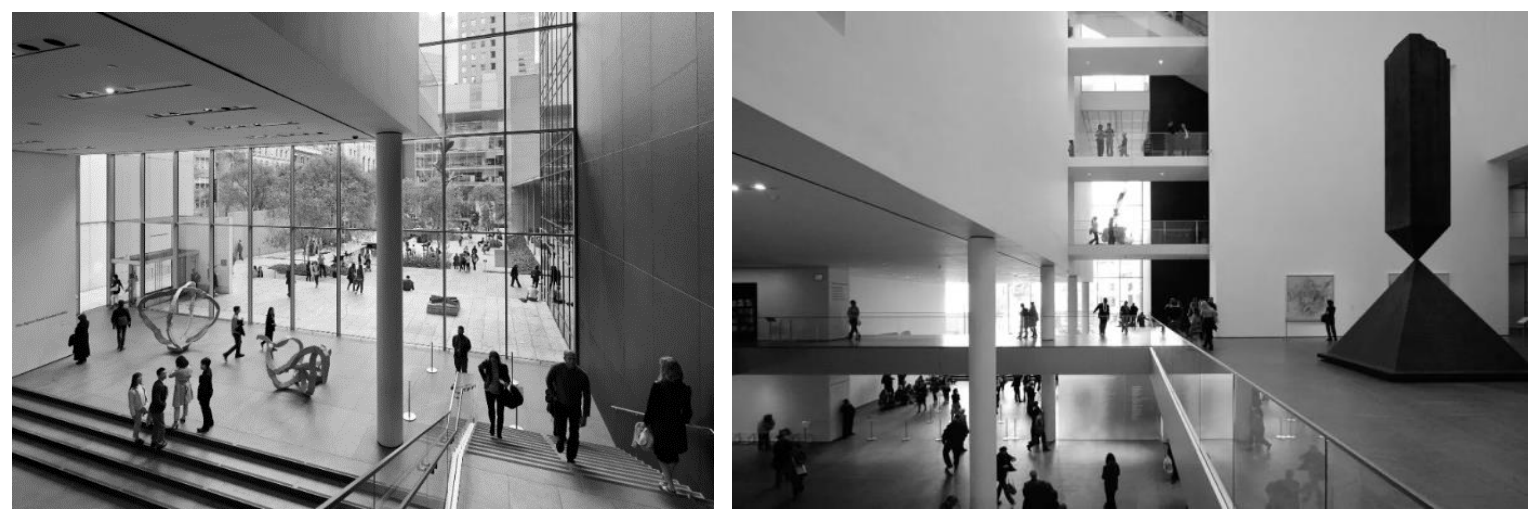

[Fig. 2] Inside the Museum with a Sense of Openness and Grid Structure[7][8]

The museum with priceless masterpieces in countless numbers chose the spirit of emptiness instead of the brand value. The reason why Taniguchi was chosen for the project aspired by the architects of the century was that the history of MoMA as well as his outstanding architectural philosophy and talent, 
were the background. It can be said that compared to the noble and elegant European art history with thousands of years of history and numerous artists and works, the artistic nutrients of the United States were very insignificant. Instead of acknowledging the "gap between the times" that Americans could never keep up with, they focused on contemporary art with the policy support of ultrarich such as Rockefeller. And they wanted to make art museums more free and open to new forms of art.

Taniguchi's plan, which utilizes a long rectangular site, provides a sense of openness that was not seen in MoMA before, instead of a colorful sculptural structure. The exhibition space was doubled and a large skylight was installed in the museum to bring natural light into the interior. In addition, major entrances were moved and large-scale research and educational buildings were newly built, taking into account the educational function of the museum[9]. Upon entering the museum, visitors can first see the beautiful scenery of the sculpture park, and the museum has an open atrium that shows the special exhibition themes of the galleries on each floor at a glance. In addition, through the organic connection between the sculpture park and each building, it was once again open to citizens. In addition, the real value of Yoshio Taniguchi's design is that MoMA has become a true symbol of New York with an architecture that visually expressed New York City's grid urban structure[10].

Eventually, Taniguchi's plan to keep MoMA's own brand upheld gained greater confidence instead of parading architect's own flashy brand. In this regard, Taniguchi's work-oriented thoughts that appropriately arranged additional exhibition spaces and educational spaces while utilizing the characteristics of the Museum of Modern Art in New York centered on the sculpture park, surpassed the remarkable imaginations of architects of the century. The long-standing unwritten rule in the architectural world, 'People who are selected are important, but the idea of selectors is more important.', was reaffirmed through this project.

\subsection{Ken Domon Museum of Photography}

This museum of photography is located in a city called Sakata in Yamagata Prefecture, Japan. The Ken Domon Museum of photography, designed by Taniguchi nearly 20 years ago, is Japan's first photography art museum that exhibits works by Ken Domon (1909-1990) born in this city, the representative of Japanese realism photography. In this project, Taniguchi did not simply design the building, but even designed an artificial lake to maximize the effect of water in the building. It was to express the flow of the Mogami River to the eastern sea in architecture. "The technique in which cube buildings of different sizes are connected by a single linear element (wall), and the space between them is empty and communicated with other spaces." that Taniguchi's iterated in the subsequent designs of the 1990s and 2000s, was embodied in this museum of photography. In the vacant space between the buildings is a beautiful courtyard that was collaboratly designed by sculptor Isamu Noguchi and landscape architect Hiroshi Teshigahara. This museum with the concept that properly tried the water and land elements, gives vitality to the fixedness of the architecture by letting the constantly changing light and shadow shine on the building of the museum, making it possible to meet the fine art created by nature every moment[11].

\subsection{Marugame Genichiro-Inokuma Museum of Contemporary Art}

It is an art museum in honor of Genichiro Inokuma, a representative Japanese modern painter. The museum, which stands in the plaza in front of the train station built to commemorate the 90th anniversary of the city and the artists born in the area, is the first impression of the city to meet when visitors to Marugame get off the train. 

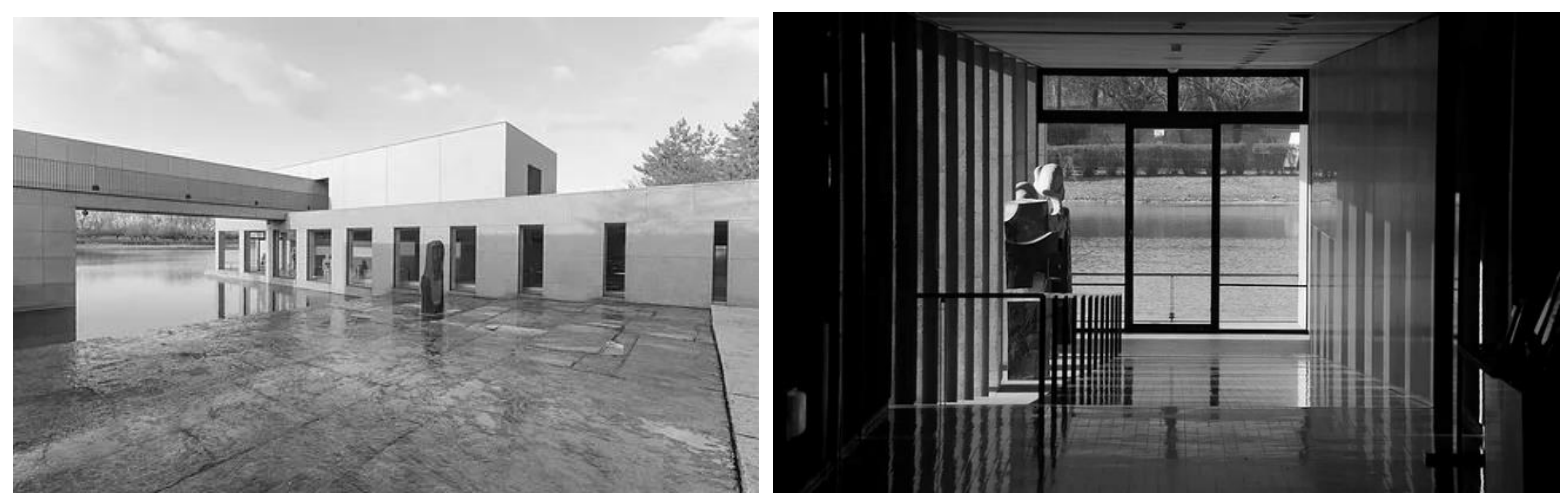

[Fig. 3] Ken Domon Museum of Photography, 1983[12]

When designing an art museum, one of the architects' big concerns was how to control the light that flows into the interior space[13]. In the museum, Taniguchi erected marble walls in front of the building, using them as a filter of light. In addition, while the walls were finished with marble, Inokuma's innocent sketches were engraved, and the deeply shaded front portal frame blocks excessive sunlight and at the same time becomes a symbol of Taniguchi's architectural design. The straight staircase in front of the sketched wall is a device that gives the space a sense of "depth" while providing circulation to go straight up to Inokuma's exhibition room[14].

In the early 1990s, Taniguchi pursued a style of creating spaces with elaborate horizontal and vertical divisions, and this museum became a decisive moment in completing such a style. His art museums form a space through a continuous surface and at the same time have flexibility that does not force appreciation and immersion in works.
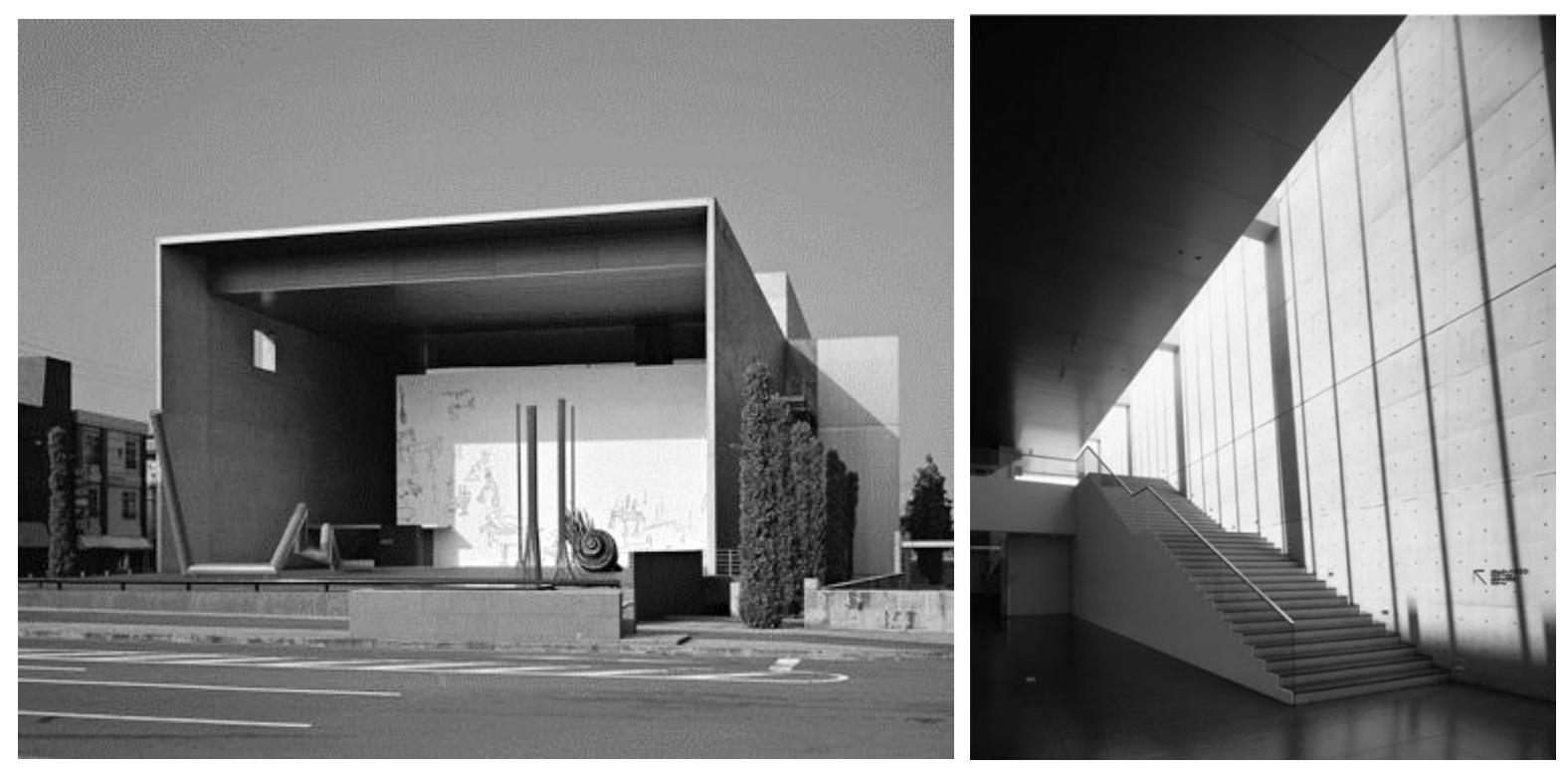

[Fig. 4] Marugame Genichiro-Inokuma Museum of Contemporary Art, 1991[15]

\subsection{The Gallery of Horyuji Treasures Tokyo National Museum}

We are familiar with the name Horyuji thanks to the mythical painter Damjing. Damjing, a Buddhist monk and painter in Goguryeo, went to Japan through Baekje, stayed at Horyuji, taught Buddhist 
doctrines and Buddhist studies, and left a masterpiece called Geumdang wall painting. While usually, the magnificent and majestic national museums of Japan lead you enter a lobby and look around in order of age or region, before entering this "treasure hall," you meet a pond first instead of a work. This is because it is designed to go around the pond in the driveway. The moment visitors face the pond who chat on the way to the museum, makes them have a reverent heart to see the best treasures in Japan[16]. Here, you can get a glimpse of the architect's mind understanding the characteristics of the exhibition hall and attempting to produce precise circulation from the entrance. A distinctive element from the outside is the frame surrounding a glass box, a unique trademark of Taniguchi. It functions to visually connect the interior and exterior while controlling the excessive light entering the building. This becomes a device like a proscenium of a performance hall that draws the attention of the inside visitors in the direction the architect intended. Upon entering the lobby, light from above in a minimalist space expresses a spatial sense with its subtle effect. I think this space shows the essence of Taniguchi's architecture. There is a wall that is completely transparent glass on one side and a heavy stone on the other side, which is closed without a single window, and the details of various finishes seem to be recreating the breathtaking Japanese craftsmanship in modern times by exerting their precision to the limit.

There is no way to overlook a single detail of the window frame, and the traces of elaboration are clear. The climax of Horyuji is revealed when entering the exhibition space through a massive stone wall. The Buddhist saints and Buddha statues in Exhibition Hall 1 are lined up to communicate with visitors as if they were born in this era, not in the past. The exact details of the exhibition display case are also elaborate enough to show the best works of Asian art.
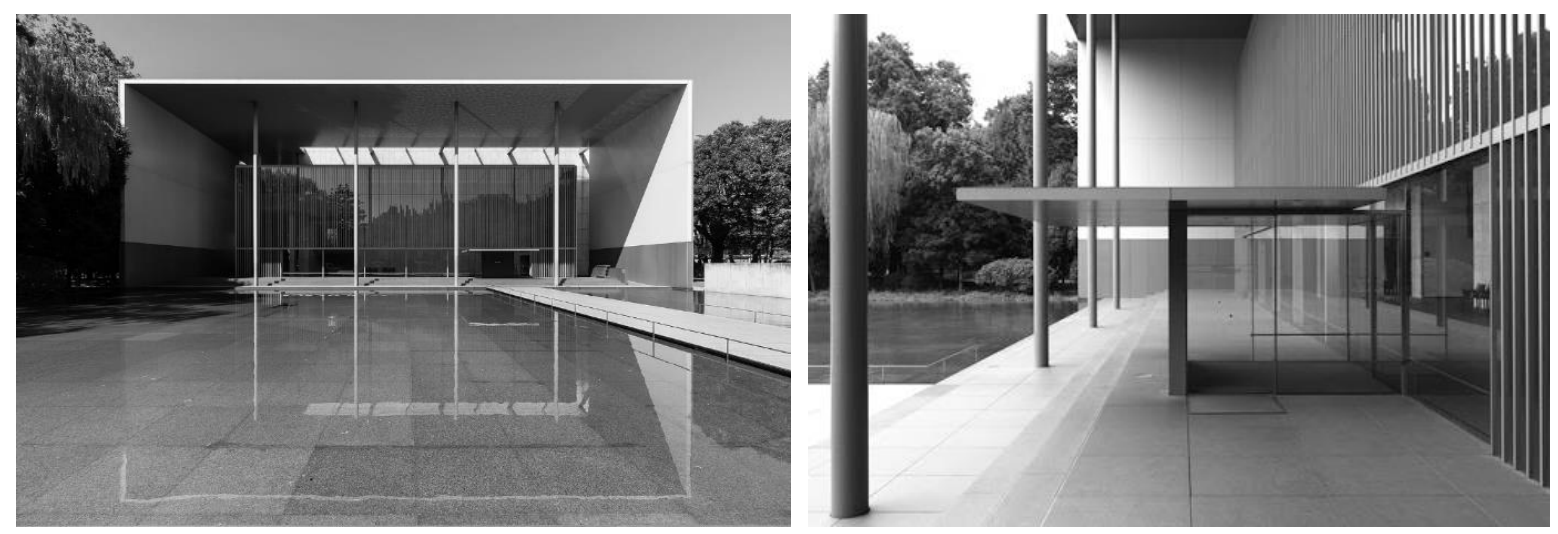

[Fig. 5] The Gallery of Horyuji Treasures Tokyo National Museum, 1999[17]

\subsection{Setouchi Art Museum}

Like the honor of Idang Kim Un-ho or Unbo Kim ki-chang among Korean traditional painters, Higashiyama Kaii (1908-1999) is a Japanese painter who received both honor and respect as a traditional painter. As a painter who expressed the unique colors and atmosphere of Japan, he took charge of gift works for foreign guests and murals for imperial use. To that extent, he was an artist in an incomparable position in Japan. Two art museums representing Japan exhibit Higashiyama's works, which are coincidentally all completed by Taniguchi's hands. The Higashiyama Kaii Gallery in Nagano Prefecture is an extension of the existing building, and the Higashiyama Kaii Setouchi Art Museum has the character of a memorial art museum only for this artist.

Taniguchi, who reflects the characteristics after considering the works to be displayed in the museum and the world of the artist's work, intensively used the painterly panorama technique, which the artist 
liked, in the architectural design in honor of Higashiyama, the traditional Japanese painter, in both art museums for Higashiyama. What The Higashiyama Kaii Gallery in Nagano Prefecture and Higashiyama Kaii Setouchi Art Museum have in common is their adoption of a method of bringing outside scenery into the interior using ribbon windows so that the painter's work and the architect's thoughts could be harmonized. The exhibition hall was designed for natural soft light to enter and diffuse into the exhibition hall, considering the nature of works, mainly landscape paintings. It is the architect's consideration to provide visitors with natural light that is the background of Japanese landscape paintings while appreciating the landscape paintings of the Japan's top artist.

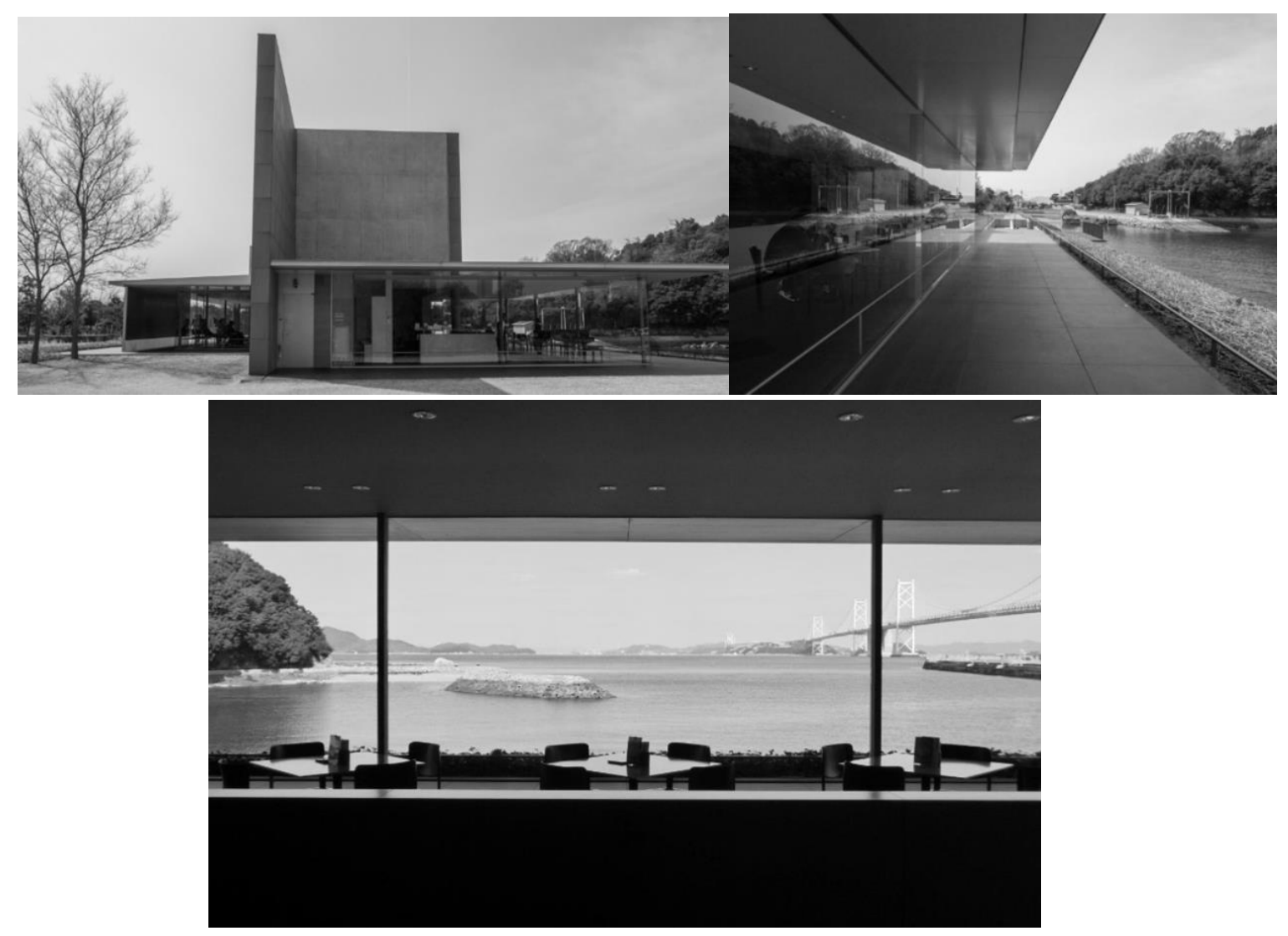

[Fig. 6] Setouchi Art Museum, 2004[18]

\section{Conclusions}

Minimalism began with paintings and sculptures produced by young American artists with minimal formative means and expressions in the late 1960s. It has the characteristics of simplicity, repetition, and organicity as it extremely excludes individual emotions and subjective expressions. It involves emptying spaces and removing decorations by emphasizing the purity of the space itself.

The characteristic of the minimalistic space in Yoshio Taniguchi's works is that it doubles the purity of the space by coloring the space with the purity of white and achromatic colors, using the restrained and simple space, using a simple and repetitive combination of geometric lines and shapes, and using an organic technique that absorbs natural elements into the space. And also his works are a simple boxshaped structure, implement artificial and natural lightings and the spirit of emptiness. In the early 1990s, Taniguchi pursued a style of creating spaces with elaborate horizontal and vertical divisions, and Inokuma Museum became a decisive moment in completing such a style.

A summary of the characteristics of minimalist space in Yoshio Taniguchi's work is shown in [Table 
1] below.

[Table 1] The Characteristics of Minimalist Space in Yoshio Taniguchi's Work

\begin{tabular}{|c|c|}
\hline Plan Elements of a Minimalist Space & Characteristics \\
\hline Transparency, light effects, simplicity & Dematerialization \\
\hline The temporality of space by movement of light & Temporality \\
\hline Openness, simplicity, repetition and unity of materials & Space extension \\
\hline Harmony of nature and locality, originality, the sense of place & Locality \\
\hline Clarity, horizontal and vertical overlap, minimality, symbolism, abstractness & Simple geometric forms \\
\hline
\end{tabular}

After all, the morphological motif of his minimalism architecture can be found in modernist thoughts of the West, but the philosophical motif and its development can be found in the view of nature of the East. This is only the harmony and wholism of nature of the East is the best way to philosophically explain the geometric and restrained form of minimalism, so it can be seen that the view of nature of the East has similarities with the concept of minimalism.” Please clarify the highlighted word.

\section{References}

[1] Lee Hyun-Kyung, Recent Strategy \& Characteristic of Worldwide Design Museums, International Journal of Art and Culture Technology, (2017), Vol.1, No.1, pp.15-20.

[2] W. Lefkowicz, 111 Museums in New York That You Must Not Miss, Emons, (2018)

[3] H. Kim, A Study on the Architectural Language and Placeness in D.T. Suzuki Museum of Yoshio Taniguchi, Jounal of the KICA, (2014), Vol.48, No.11, pp.15-22.

[4] J. Kim, A study of Monolithic Design and Contemporary Architecture Space Constitution, Jounal of the Korean Institute of Interior Design, (2017), Vol.26, No.1, pp.3-12.

[5] https://www.moma.org/magazine/articles/125, Feb 15 (2021)

[6] T. Riley, Y. Taniguchi, Yoshio Taniguchi: Nine Museums, The Museum of Modern Art, (2004)

[7] https://www.headout.com/blog/museum-of-modern-art-nyc/ , Feb 10 (2021)

[8] https://heintges.com/moma-philip-johnson/ Jan 20 (2021)

[9] Donghyeog Choi, Yujin Seo, A Study on the Urban Regeneration Planning Elements for the Pedestrian-Friendly City Environment, International Journal of Art and Culture Technology, (2017), Vol.1, No.1, pp.9-14.

[10] J. Lee, A study on the Expressional Characteristics of Museum Architecture of Yoshio Taniguchi, Jounal of the Korean Institute of Interior Design, (2013), Vol.15, No.2, pp.106-111.

[11] www.domoken-kinenkan.jp/, May 15 (2021)

[12] https://www.thehiddenjapan.com/kendomon/, Jan 10 (2021)

[13] Song Du-jin, Kim Yong-seong, A Basic Study on Interaction Spaces from the Perspective of Human Behavior, International Journal of Art and Culture Technology, (2018), Vol.2, No.2, pp.19-24.

[14] Donghyeog Choi, Sohyun Jeoun, A Study on the Planning Elements for the Block Unit Development Plan based on the Community Street, International Journal of Art and Culture Technology, (2017), Vol.1, No.1, pp.1-8. 
[15] https://www.tokyoartbeat.com/venue/D42717AE.en/, Feb 25 (2021)

[16] Y. Ahn, J Kim, A Study on Revitalization Design of Culture and Art Space Based on Place Memory, Journal of the Korea Institute of Spatial Design, (2016), Vol.11, No.5, pp.105-117.

[17] http://figure-ground.com/horyuji/0003/, Feb 5 (2021)

[18] https://www.my-kagawa.jp/en/see-and-do/10099/, May 15 (2021) 